\title{
Emergency Workers' Quality of Life: The Protective Role of Sense of Community, Efficacy Beliefs and Coping Strategies
}

\author{
Elvira Cicognani $\cdot$ Luca Pietrantoni $\cdot$ Luigi Palestini $\cdot$ Gabriele Prati
}

Accepted: 5 January 2009/Published online: 14 January 2009

(C) Springer Science+Business Media B.V. 2009

\begin{abstract}
This study, involving a sample of 764 emergency workers, investigates dimensions of quality of life at work (Compassion fatigue, Burnout and Compassion satisfaction), and their relationships with Coping strategies and some psychosocial variables (Sense of Community, Collective Efficacy and Self-efficacy). Results indicate the usefulness of distinguishing between positive and negative indicators of emergency workers' quality of life. Compassion satisfaction is positively correlated with efficacy beliefs, Sense of Community and the use of Active coping strategies. Burnout and Compassion fatigue are especially correlated with the use of dysfunctional coping strategies like distraction and self-criticism. Volunteer emergency workers enjoy a higher well being than full-time professional workers. Results and their implications for interventions aimed at increasing rescue workers' quality of life by enhancing psychosocial competences are discussed.
\end{abstract}

Keywords Emergency workers - Quality of life - Self-efficacy · Collective efficacy · Sense of community · Coping

\section{Introduction}

The scientific literature on emergency workers has put an increasing focus on psychological distress resulting from repeated exposure to traumatic events experienced as part of a person's everyday work. Negative outcomes include, for example, posttraumatic stress disorder (PTSD), Compassion fatigue (Figley 1995, 1999) and a sense of low personal accomplishment and emotional exhaustion (Figley 1998). Indeed, emergency services workers repeatedly attend traumatic events and are consequently exposed to a double

This research was funded by the Italian Ministry of University and Scientific Research as Project of Relevant National Interest ("Individual and social competences in the management of critical events in the community. Proposal of an intervention model”) (2005-2007) (Scientific Resp. Elvira Cicognani).

E. Cicognani $(\bowtie) \cdot$ L. Pietrantoni $\cdot$ L. Palestini · G. Prati

Department of Sciences of Education "G.M. Bertin", University of Bologna, Via Filippo Re, 6,

40127 Bologna, Italy

e-mail: elvira.cicognani@unibo.it 
stress, stemming from the traumatic event itself and from helping the victims (Fullerton et al. 1992; Hytten and Hasle 1989; Raphael 1986). Moreover, since emergency work falls into a wider range of public service occupations, there is a growing community concern about the undesirable consequences of risking one's life — and saving others' — on a daily basis (Cowman et al. 2004).

\subsection{Quality of Life in Emergency Workers}

Emergency workers' quality of life is associated to their high levels of exposure to critical incidents, and scientific research has pointed out how this exposure is related to higher levels of mental health risk (Weiss et al. 1995). A critical incident may be any event that has a stressful impact sufficient enough to overwhelm an individual's sense of control, connection and meaning in his/her life.

The literature has initially focused on posttraumatic psychological difficulties, such as post traumatic stress disorder (PTSD), as the main effect of exposure to critical incidents. Findings range from the prevalence of PTSD diagnoses (e.g., Wagner et al. 1998) to the longitudinal presence of posttraumatic symptomatology (e.g., Marmar et al. 1999; Ursano et al. 1995).

However, emergency workers are not necessarily affected by the impact of events themselves and their experience of trauma usually comes from helping suffering people (Beaton et al. 1998): in this sense, a major issue concerns secondary exposure to extremely stressful events which results in a secondary traumatic stress, or Compassion fatigue (Figley 1995).

A second issue stemming from the helping nature of emergency work is the risk of developing a Burnout syndrome, defined as a combination of an overwhelming exhaustion, feelings of cynicism and detachment from the job, and a sense of ineffectiveness and lack of accomplishment. There is a wide range of emergency work characteristics that are consistently related to Burnout, such as perceived workload and time pressure, clientrelated stressors (e.g., problems in interacting with victims, confrontation with death and dying), emotional demands of working with other people in a care giving role and other emotion-work variables (e.g., requirement to suppress emotions on the job and/or to be emotionally empathic) (Maslach et al. 2001). In this regard, recent research shows that a frequent exposure to critical incidents in ambulance personnel is not only related to posttraumatic symptomatology, but also to higher levels of Burnout (Alexander and Klein 2001).

Even though Compassion fatigue and Burnout are similar in the feelings they create (e.g., helplessness, loneliness, anxiety, depression), they have a central difference. While Burnout is generated by an excessive and prolonged job stress (Cherniss 1980), Compassion fatigue is the sudden result of exposure to job-related stressful events (Figley 1995).

Nevertheless, we should notice that posttraumatic difficulties, Compassion fatigue and Burnout are not the only possible emergency work-related outcomes. For example, Stamm (2002) introduces the concept of Compassion satisfaction, defined as the benefits that individuals derive from working with traumatized or suffering persons. These benefits include positive feelings about helping others, contributing to the work setting and even to the greater good of society, and the overall pleasure derived from being able to do one's work well. Thus, emergency workers' quality of life should not be reduced to the absence of negative consequences, and the focus should also be aimed at clarifying the positive effects of a helping profession. Investigating all possible outcomes could lead to a more 
complete and holistic comprehension of emergency work-related quality of life and its predictors.

Scientific research has focused increasing attention on the correlates of reactions to critical incidents in emergency services personnel (Marmar et al. 1999; Regehr et al. 2000; Weiss et al. 1995), particularly among professional rescue workers (e.g., fire fighters, health personnel). In this context, we will focus on coping strategies and on the role of protective factors at an individual (e.g., self-efficacy), organizational (e.g., perceived collective efficacy) and community (e.g., sense of community) levels.

\subsection{The Importance of Sense of Community and Efficacy Beliefs for Emergency Workers}

McMillan and Chavis (1986) describe sense of community (SOC) as a feeling of belongingness and attachment to a place, accompanied by a sense of shared history and connection with other members of the community. Whereas the concept of SOC applies to a variety of contexts, most authors generally analyse it referring to a geographically defined community and to the ties that link people to their place of residence. This bond has been found associated to a wide range of positive psychological outcomes, such as subjective well-being and life satisfaction (e.g., Davidson and Cotter 1991; Prezza et al. 2001; Fisher and Sonn 2002).

The role of sense of community in understanding emergency workers' quality of life has not been previously considered in the literature. Some peculiarities of such profession might, however, call for the usefulness of such construct as explanatory variable. As a preliminary consideration, it is worth noticing that this occupation usually takes place on a local basis, sometimes involving critical events affecting a whole community or a significant part of it (e.g., in case of natural or technological disasters). Knowledge of the community context, both in its geographical characteristics and in the social and structural aspects, is important for guaranteeing an efficient and coordinated intervention among the different categories of professionals involved when critical events occur. Moreover, emergency workers' activity is aimed at alleviating suffering (and saving lives) of individuals and groups, which may belong to their own community: it is clearly an occupation which requires a pro-social orientation, as testified by the high numbers of volunteer rescue personnel. Their activity is highly valued and has strong positive connotations, commonly recognized by the whole society. The impact of rescue workers' activity on the lives of many people is evident, and is a source of gratifications when successful. Such considerations suggest that emergency workers' Sense of Community, which includes, according to McMillan and Chavis's (1986) model, dimensions like feeling of belonging and emotional connection with the community, perceived influence over it and perceived opportunities for satisfying one's needs through such belonging, may be particularly important for rescue personnel, and may constitute a contributing factor to their quality of life. Emotional connection with the community and perceived influence over other people's condition might also protect emergency workers from negative outcomes stemming from the occurrence of unsuccessful interventions (e.g., involving casualties). In the literature, we found only one study where the construct of Sense of Community has been investigated in this population (in particular, fire fighters) (Cowman et al. 2004); however, in such research, the construct was examined at the organizational level as the perception of belonging to a community of co-workers.

At the organizational level, further dimensions of the work group context may be important in enhancing emergency workers' quality of life. Among these, there is 
perceived Collective Efficacy. The concept of Collective Efficacy refers to what people choose to do as a group, the effort they put into it and the perception of the group's ability to accomplish its major tasks (Bandura 1997). This occupation, owing to its characteristics, requires to work collaboratively and in a coordinated way as a group: no rescue worker can be effective working alone without making reference to an organization. Dealing with critical experiences and being able to cope with them creates a series of assumptions and beliefs about the situations a group can master. As a consequence, the expectation of success influences the outcome of the performance, as it shapes the way group members react to critical incidents. In this perspective, perceived Collective Efficacy enhances job satisfaction and well being (Jex and Thomas 2003).

Even though perceived Collective Efficacy should be considered as an emergent grouplevel property, it is not independent of the beliefs and actions of the individuals who make up the group (Bandura 2001). Taking into account the interdependence between individual workers and their team, we suggest that in the emergency work environment the perception of efficacy of the group in solving a critical situation is not independent from individual worker's skills and perceived competences (Self-efficacy). Self-efficacy beliefs share similar functions and processes with Collective Efficacy but are focused on the individual level (Bandura 1997). When addressing the issue of emergency workers' quality of life, Self-efficacy becomes a crucial element. Previous research has shown that cognitive appraisal of Self-efficacy is an important factor in reducing levels of distress (Gibbs 1989; McCammon et al. 1988) and it is associated with lower levels of traumatic stress symptoms and depression in fire fighters (Regehr et al. 2000). Cognitive mastery of an event has been found as frequently used by emergency workers (McCammon et al. 1988). Contrary to perceived Collective Efficacy, which is more affected by contingent factors (e.g., quality of group relationships and coordination), Self-efficacy is likely to increase with experience and level of expertise.

\subsection{Coping Strategies and Mental Health Among Emergency Workers}

A growing number of studies have explored the contribution of coping strategies to mental health among rescue personnel. As emergency workers are a self-selected occupational group which faces unusual demands, they may not be compared with the general population in term of coping strategies (Mitchell and Bray 1990). In this population it is more difficult to establish, on a priori grounds, which coping strategies can be considered more effective in facing stressors and in improving quality of life. For example, situations involving casualties might be perceived as more stressful by rescue workers using a problem-solving oriented coping style than by those who are more capable to use acceptance and cognitive restructuring coping strategies. The complexity of the situations faced by rescue workers is paralleled by findings from the empirical literature. With the exception of avoidance coping, results concerning the relationship between coping strategies and mental health outcomes in rescue personnel are not always consistent. Results seem to indicate that the use of cognitive and behavioral avoidance, commonly observed after a trauma, predict greater psychological distress among professional fire fighters and ambulance personnel (Brown et al. 2002; Clohessy and Ehlers 1999; Chang et al. 2003; Marmar et al. 1996). Problem-focused coping has been found associated both to high (Marmar et al. 1996) and low levels of distress (Brown et al. 2002) among fire fighters. The use of emotion-focused coping has been associated to lower psychological distress (Brown et al. 2002) but seeking social support for emotional reasons and venting of emotions are not (Clohessy and Ehlers 1999). Finally, fostering positive attitudes does not predict future 
changes in self-reports of posttraumatic stress (Clohessy and Ehlers 1999) while positive reappraisal has been found to predict a posttraumatic symptomatology (Chang et al. 2003). Summarizing these findings we can conclude that, at least amongst professional emergency workers, the evidence on the impact of coping on workers' well being is more consistent for some strategies (e.g., avoidance-oriented coping) than for others (e.g., cognitive restructuring). Further, most research reviewed has been conducted on professional emergency workers. We do not have much information on coping strategies and quality of life among volunteer emergency workers.

\section{Aims and Hypotheses}

This study aims at investigating emergency workers' quality of life and its relationships with some psychosocial variables; in particular, we considered coping strategies, Selfefficacy, Collective Efficacy and Sense of Community. Owing to the paucity of information on the role of occupational status, we included both professional rescue workers and volunteers in order to assess similarities and differences in the variables investigated.

Departing from previous research, in the assessment of quality of life a decision was taken to focus not only on posttraumatic symptoms and on negative outcomes in a wider sense but to introduce an additional assessment of positive consequences of emergency work. We therefore operationalised quality of life using three indicators: Compassion fatigue, Burnout, and Compassion satisfaction. A higher level of quality of life should correspond to lower perceptions of fatigue and Burnout and a higher Compassion satisfaction (Stamm 2002).

Based on the literature, the hypotheses were the following.

H1: Considering the self-selected nature of this occupation, we expected that the general population of emergency workers would enjoy overall satisfactory levels of quality of life, particularly volunteer rescue workers. In fact, among professional workers, the degree of involvement in such occupation (e.g., in terms of working hours) and their motivations include also considerations about salary and potential consequences of abandoning this job and finding a different one if work conditions become unsatisfactory. As a consequence, they might prefer to tolerate stressful work conditions, if they feel that alternatives are not available. Volunteer workers are less subjected to such considerations, as their continuing participation to rescue activity is more directly related to their pro-social motivation. These differences might impact on levels of quality of life.

$\mathrm{H} 2$ : Considering the role of coping strategies, our hypothesis was that the use of problem-solving oriented coping strategies (e.g., active coping, positive reframing, planning, search for instrumental support) would be positively associated with emergency workers' quality of life (higher Compassion satisfaction). However, considering that rescue workers are also confronted with situations in which their intervention does not produce positive outcomes (e.g., casualties despite their efforts to save people), we also expected that the use of problem solving strategies would be positively associated with levels of Burnout and Compassion fatigue. The use of avoidance-oriented coping strategies (e.g., distraction, self-criticism, denial) was expected to increase negative outcomes. As regards the role of occupational status, even though we lacked previous evidence, we expected a higher use of distraction coping strategies among professional workers.

H3: Sense of Community was expected to significantly increase quality of life in its positive indicators (Compassion satisfaction), and to reduce those negative outcomes 
that are more associated to prolonged and chronic stress (Burnout). SOC should be less relevant in understanding rescue workers' emotional experience associated with secondary exposure to sudden traumatic events (Compassion fatigue).

H4: As regards perceived Collective Efficacy, expectations were that it should be positively associated with rescue workers' quality of life (Jex and Thomas 2003).

H5: On the basis of previous research (e.g., McCammon et al. 1988; Regehr et al. 2000) we expected that emergency workers with stronger Self-efficacy would show a higher quality of life, in all three dimensions (higher Compassion satisfaction and lower Burnout and Compassion fatigue).

The analysis of these hypotheses will include an examination of gender and length of service, since previous research has shown that these factors may have an effect on emergency workers' quality of life (e.g., Chang et al. 2003; Dean et al. 2003; Spinhoven and Verschuur 2006).

\section{Method}

\subsection{Instrument}

The instrument consisted in an on-line questionnaire, including the following areas:

Demographics included were questions on gender, age, occupational status (volunteer or full-time emergency worker), length of service, and level of education.

Quality of life was assessed by the ProQOL R-IV (Professional Quality of Life Scale. Compassion Satisfaction and Fatigue Subscales-Revision IV), including 30 items corresponding to three scales: Compassion Satisfaction Scale, Burnout Scale and Trauma/Compassion Fatigue Scale (Stamm 2005). Participants were asked to specify how often, during the last month, they had experienced a series of emotional states. Responses were given on a five-point Likert scale, ranging from "never" to "very often".

Coping strategies were assessed using the Brief COPE Inventory (Carver 1997), including 28 items measuring fourteen coping strategies (Self-distraction, Active coping, Denial, Substance use, Emotional support, Instrumental support, Behavioral disengagement, Venting, Positive reframing, Planning, Humor, Acceptance, Religion, Selfblame). Participants were asked to think about the more recent stressful events occurred during their work activity and to indicate the extent to which they coped with them using the different strategies. Answers were provided on a five-point Likert scale (from "never" to "very often").

Sense of Community was assessed by the "Italian Sense of Community Scale" (Prezza et al. 1999). From the original version, four items were dropped because were deemed inappropriate or irrelevant for this population (e.g., they measured attachment to their home). Response alternatives were on a five-point Likert scale from "strongly agree" to "strongly disagree". An overall score of Sense of Community was created, after reversing the negatively worded items, so that higher scores indicated higher Sense of Community. Cronbach $\alpha$ is .82.

Collective Efficacy was measured by the "Perceived Collective Efficacy for members of volunteering associations" by Barbaranelli and Capanna (2001), including five items. The instrument measures the extent to which members perceive their association or organization capable to face different situations and critical events occurring during their 
typical everyday activity. Response alternatives are provided on a five-point Likert scale from "completely agree" to "completely disagree". An overall score was calculated in such a way that higher scores correspond to higher Collective Self-Efficacy. Cronbach $\alpha$ was .83 .

Self-efficacy was assessed by the "Perceived Personal Efficacy for members of volunteering associations" by Barbaranelli and Capanna (2001). The instrument includes 18 items, assessing the extent to which members of associations feel capable to face the challenges arising from their activity. Response alternatives are provided on a five-point Likert scale from "never" to "very often". An overall score was calculated so that higher scores correspond to higher personal Self-efficacy. Cronbach $\alpha$ is .77.

\subsection{Procedure}

To collect the data, the on-line questionnaire was posted on the webpage of the Emergency Psychology Group of the Faculty of Psychology of the University of Bologna (http://emergenze.psice.unibo.it/ricerca.soccorritori.html). Included was also a general introduction on the purpose of the research and a consent form to be signed as a precondition to proceed with the completion of the questionnaire. In order to obtain a wide representation of the different typologies of emergency work personnel in the Italian context, prior to the beginning of the study, which was conducted in Spring 2007, an e-mail message was sent to the webmasters of the principal Italian organizations of emergency workers (Fire fighters, Civil Protection, Emergency Intervention Services, Red Cross), at a national, regional and local levels. The mail included a presentation of the study and a request for collaboration by linking the questionnaire web page to their official web site to encourage their members to fill it. The choice of the on-line questionnaire was considered appropriate since most emergency workers of these organizations are regular users of the official web page, where they can find different sorts of information. This allows both to collect a considerable amount of data within a limited time frame and to have a fairly good representativeness of the sample with respect to members of such associations. A positive reply was obtained from the Department of Civil Protection, the National Association of Fire fighters, the European Organization of Fire fighters, Civil protection and Environmental protection, the Association of Italian Fire fighters, Emergency Intervention Services and Local Red Cross associations of two Regions in North Italy. Moreover, as questionnaires started to be filled, it became clear that some of the organizations contacted had spread the information on the study among their members, without explicitly informing us that they had received our message and agreed to collaborate, so, the number of participating organizations was actually higher. A high number of questionnaires were filled during the week after the posting of the questionnaire. Since the number of questionnaires filled per day lowered with time, we decided to consider the questionnaires completed within 60 days from the posting of the questionnaire.

\subsection{Missing Data Analysis}

Subjects who had filled out less than $50 \%$ of the questionnaire were excluded from the analyses $(N=27)$. After this deletion of cases there were no variables with more than $5 \%$ missing values. Using the EM (expectation-maximization) method, we conducted Little's MCAR test to examine whether the missing data were random. The Chi-square was significant suggesting our missing data were not completely at random $\left(\chi_{(12631)}^{2}=13,405.90\right.$, 
$p=.000)$. According to Schafer and Graham (2002) we imputed missing values with the EM (expectation-maximization) methods using NORM v. 2.03 software (Schafer 2000) to produce a data set without missing data.

\subsection{Participants}

The final sample includes 764 emergency workers, $71.3 \%$ male and $28.7 \%$ female. Age ranges from 18 to 66 years $(M=34$ years). They include fire fighters, Civil Protection volunteers, different categories of emergency medical service personnel (medical first respondents, medical technicians, paramedics, nurses, ambulance personnel, ambulance drivers). $78.4 \%$ are volunteers and the remaining $21.6 \%$ are full-time emergency workers. Women are slightly over-represented than men among volunteers $(83.1$ vs. $76.5 \%)\left(\chi_{(1)}=4.008, p=.027\right)$. Level of education is medium-high: $14.7 \%$ of the sample completed compulsory education, $56.3 \%$ has a high school degree and the remaining $29.1 \%$ a university degree. Women have higher level of education (high school and university degree) than men $\left(\chi_{(3)}=36.887, p=.000\right)$. Moreover, level of education is higher among full-time workers $\left(\chi_{(3)}=14.394, p=.003\right)$. Length of service ranges from 1 to 36 years $(M=9.38 ; \mathrm{SD}=7.36)$.

\section{Results}

In the following, we will firstly present the results concerning quality of life and psychosocial variables, and differences according to emergency workers' occupational status, gender and length of service. We will then present correlations between quality of life and the other variables.

\subsection{Professional Quality of Life}

The ProQOL was subjected to Factor Analysis procedures. The univariate and multivariate normality of all the items were examined prior to conducting the factor analysis, and a number of items were found to have unsatisfactory skewness and/or kurtosis (DeCarlo 1997). A preliminary inspection of the descriptive statistics lead to discard eight items owing to unsatisfactory psychometric properties or cultural inappropriateness for the Italian context. Therefore, principal axis factoring was used because it does not make distributional assumptions (Fabrigar et al. 1999). We chose direct quartimin rotation strategy because, according to the theoretical model, we expected significant factor intercorrelations. Visual inspection of the scree plot, ease of interpretation, and theory indicated that the three-factor solution was the best fit.

The first factor ("Compassion Satisfaction") includes the items from the Compassion Satisfaction Scale and two items from the Burnout Scale (Variance explained $=17.659 \%$ ) $(\alpha=.86)$; the second factor ("Burnout") includes four items from the Burnout scale and three items from the Trauma/Compassion Fatigue Scale showing higher loadings on this factor than on the original scale (Variance explained $=11.919 \%)(\alpha=.79)$ and the last one ("Compassion fatigue") includes five items of the Trauma/Compassion Fatigue scale and one item from the Burnout scale (Variance explained $=10.493 \%)(\alpha=.76)$.

Subscale mean scores were calculated by averaging across the specific items included into the three factors (see Table 1). The Burnout and Compassion fatigue scales are positively and highly correlated $(r=.599, p=.000)$, whereas the Compassion 
Table 1 Variables of the study: descriptive statistics

\begin{tabular}{llccc}
\hline Variables (range 1-5) & $M$ & SD & Skewness & Kurtosis \\
\hline Professional quality of life & & & & \\
$\quad$ Compassion Satisfaction & 3.9311 & .565 & -.45 & .85 \\
$\quad$ Burnout & 1.8439 & .629 & 1.03 & 1.42 \\
$\quad$ Compassion Fatigue & 1.6579 & .573 & 1.44 & 3.06 \\
Coping strategies & & & & .27 \\
$\quad$ Active coping & 3.3652 & .738 & -.44 & -.42 \\
Positive reappraisal & 2.7866 & .925 & -.01 & -.19 \\
$\quad$ Support/venting & 2.6350 & .766 & .09 & -.65 \\
$\quad$ Humor & 2.4188 & 1.122 & .42 & -.50 \\
$\quad$ Distraction & 2.3547 & .956 & .39 & -.22 \\
$\quad$ Religion & 2.0190 & 1.012 & .80 & .13 \\
$\quad$ Self-criticism & 1.9771 & .804 & .64 & .74 \\
Sense of Community & 3.6365 & .497 & -.69 & .38 \\
Collective Efficacy & 3.8194 & .796 & -.82 & .26 \\
Self-efficacy & 3.8858 & .372 & -.24 &
\end{tabular}

Satisfaction scale negatively weakly correlates with the Burnout Scale $(r=-.092$; $p=.011$ ). These results indicate that positive and negative dimensions of quality of life are clearly distinct.

To test differences in scores of Compassion Satisfaction, Compassion Fatigue and Burnout according to participants' gender and occupational status, a MANOVA was conducted. Results indicated the presence of main effects of dimension of quality of life, $F_{(2,760)}=1,830,792, p=.000$, gender, $F_{(1,760)}=7.372, p=.007$ and occupational status, $F_{(1,760)}=6.146, p=.013$. Moreover, significant interactions with quality of life dimensions were found between both gender, $F_{(2,760)}=11.975, p=.001$ and occupational status, $F_{(2,760)}=18.273, p=.000$. Female rescue workers score higher than male on Burnout (female $M=2.06, \mathrm{DS}=.63$; male $M=1.84$, DS =.62) and Compassion Fatigue (female $M=1.84$, DS $=.56$; male $M=1.62$, DS $=.57$ ), and lower on Compassion Satisfaction (female $M=3.83$, DS $=.51$; male $M=3.93$, DS $=.58$ ). Moreover, volunteer rescue workers score higher than professional workers on Compassion Satisfaction (volunteers $M=3.93$, DS $=.55$; professional $M=3.83$, DS $=.58$ ) and lower on Burnout (volunteers $M=1.81, \mathrm{DS}=.59$; professional $M=2.10$, DS $=.71$ ) and Compassion Fatigue (volunteers $M=1.67$, DS $=.56$; professional $M=1.79$; DS $=.60$ ). No significant correlation was found between length of service and quality of life.

\subsection{Coping Strategies}

Items of the Brief-COPE were subjected to Factor Analysis. Preliminary item analyses lead to discard the items from the subscales: Substance use (Kurtosis $=59.97$ ), Denial (Kurtosis $=11.16)$ and Behavioral disengagement (Kurtosis $=1.54)$ owing to unsatisfactory psychometric properties. Factor analysis conducted on the remaining 22 items showed seven factors. The first factor includes six items from three subscales: Emotional support, Instrumental support and Venting $(\alpha=.79)$. The second factor includes Active coping and Planning. Items of the Acceptance subscale loaded on this factor but were 
discarded owing to very low factor loadings. Alpha for the remaining four items is .69. The third factor corresponds to Humor $(r=.78)$; the fourth factor to Religion $(r=.67)$; the fifth to Self-distraction $(r=.51)$, the sixth to Self-criticism $(r=.49)$ and the last one to Positive reappraisal $(r=.44)$.

Subscale scores were calculated by averaging across the means of the specific items included into the seven factors (see Table 1). Correlations between subscales are almost all significant and positive (with the exception of correlations between Humor and Active coping and Religion), and range from $r=.073(p=.044)$ to $r=.314(p=.000)$.

Most frequently used coping strategies by the sample are Active coping and Positive reappraisal, followed by Support/Venting. Self-criticism and Religion are less frequently used.

MANOVA conducted to test differences in coping strategies according to participants' gender and occupational status indicated a main effect of strategy, $F_{(6,760)}=105.028$, $p=.000$ and a main effect of gender, $F_{(1,760)}=12.966, p=.000$. Moreover, significant interactions were found between coping strategies and gender, $F_{(6,760)}=4.902, p=.027$, and between coping strategies and occupational status, $F_{(6,760)}=5.918, p=.015$. More specific analyses indicated that female rescue workers, more than male, tended to use Religion $\left(M=2.15, \mathrm{DS}=1.00\right.$ vs. $\left.M=1.96, \mathrm{DS}=1.01 ; t_{(762)}=-2.406, p=.016\right)$, Support/Venting $\left(M=2.96, \quad \mathrm{DS}=.74 \quad\right.$ vs. $M=2.50, \quad \mathrm{DS}=.73 ; t_{(762)}=-7.818$, $p=.000)$, and Self-criticism $\left(M=2.18, \mathrm{DS}=.77\right.$ vs. $M=1.89, \mathrm{DS}=.84 ; t_{(762)}=$ $-4.637, p=.000)$. Volunteers score higher than full-time emergency workers on Support/ Venting $\left(M=2.68, \mathrm{DS}=.77\right.$ vs. $\left.M=2.46, \mathrm{DS}=.71 ; t_{(762)}=3.285, p=.001\right)$ and lower in Distraction $\left(M=2.26\right.$, DS $=.92$ vs. $M=2.68, \mathrm{DS}=.99 ; t_{(762)}=-5.042$, $p=.000)$.

\subsection{Efficacy Beliefs}

Table 1 shows mean scores of Collective Efficacy and Self-efficacy. Differences in scores of Collective Efficacy were found between volunteer and full-time emergency workers: the former score higher than full-time workers $(M=3.89$ vs. $M=3.56)\left(F_{(1,763)}=13.987\right.$, $p=.000)$.

\subsection{Sense of Community}

Table 1 shows mean scores of SOC. ANOVA indicated the presence of main effects of gender, $F_{(1,763)}=11.594, p=.001$, occupational status, $F_{(1,763)}=6.774, p=.009$, as well as a gender by occupational status interaction, $F_{(1,763)}=5.609, p=.018$. Sense of community is lower among female professional emergency workers $(M=3.35$, DS $=.47)$ than among the other groups (male professional emergency workers $M=3.65$, DS $=.50$; female volunteer workers $M=3.61$, DS $=.52$; male volunteer workers $M=3.66$, $\mathrm{DS}=.49)$. No significant differences were found according to length of service.

\subsection{Correlates of Quality of Life}

Table 2 shows correlations among all the variables. Given that low correlation values (for example $r= \pm$.2) cannot be actually interpreted in terms of meaningful correlations, we considered as meaningful correlation coefficients around .3 or above. 


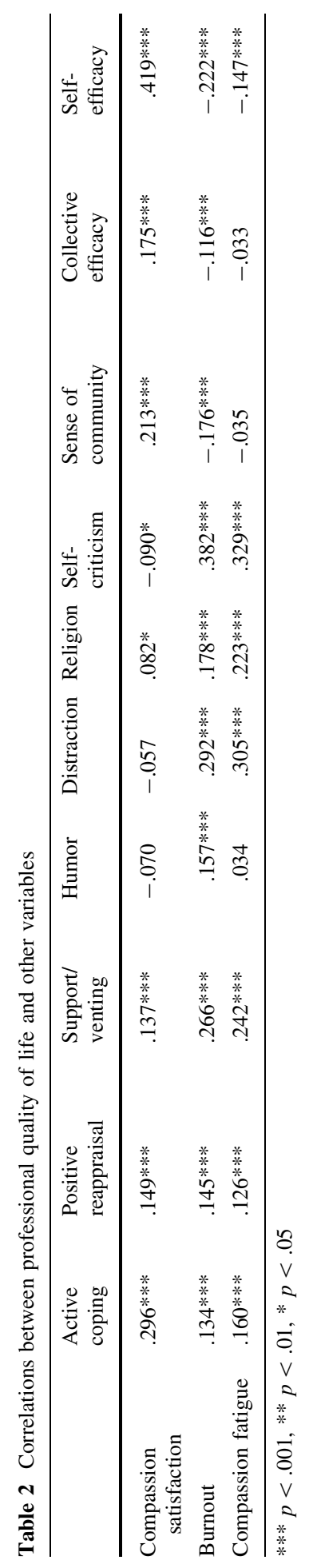


Results indicated that the use of active coping positively correlated with all three quality of life indicators, and especially with Compassion Satisfaction. Support/venting was also positively correlated with both positive and negative indicators of quality of life, but especially with Burnout. Distraction and Self-criticism were positively associated with negative well being outcomes. Sense of community and collective efficacy slightly correlated with well being outcomes (Compassion Satisfaction). Self-efficacy was strongly related to compassion satisfaction.

\section{Discussion}

Emergency workers' quality of life is currently extensively investigated, even though studies focus mostly on negative outcomes of exposure to critical incidents, affecting a minority of them. In this study we included both negative (Compassion fatigue and Burnout) and positive outcomes of emergency work (Compassion satisfaction) in order to have a broader picture, particularly on the general population of emergency personnel, most of which do not develop PTSD or other serious symptoms. Of particular interest was the role of some protective factors, like Self-efficacy, Collective efficacy among coworkers and Sense of Community, and coping strategies.

Results confirmed the usefulness of distinguishing between different quality of life outcomes in order to better understand emergency workers' emotional experience. Internal comparisons showed, however, that females and full-time emergency workers are more vulnerable to negative outcomes, and especially Burnout; this finding is paralleled by the higher use of avoidance-oriented coping strategies by these subgroups.

Further support for the distinctiveness of the three dimensions of quality of life comes from the nature of their psychosocial correlates. Among coping strategies, especially the use of Self-criticism and Distraction, are significantly associated with Burnout and Compassion fatigue outcomes. Compassion satisfaction (including positive feelings about helping activity), is strongly correlated with Self-efficacy as well as with the use of Active coping.

The role of support in this sample is more ambiguous, partly because instrumental and emotional functions of support (the former traditionally considered as an active strategy and the latter a more avoidance-oriented one) emerged as part of the same component in factor analysis. The use of Religion and Humor seems to only slightly reduce emergency workers' quality of life.

Volunteer emergency workers perceive a stronger Collective Efficacy than full-time; moreover, length of service (and expertise) is associated with higher Self-efficacy and a stronger use of Active coping strategies. Volunteer emergency workers thus appear to enjoy a better quality of life and are more equipped with resources to face stressors associated with rescue work compared to full-time rescue personnel. The higher vulnerability of full-time emergency workers, compared to volunteers, can be partly attributable to the fact that the former are "public officers" selected through public competition for such occupation and receive their salary from the State. Their degree of involvement in such occupation (e.g., in terms of working hours) as well as their motivations for such profession partly differs from volunteers, and include also considerations about salary and potential consequences of abandoning this job and finding a different one if work conditions become unsatisfactory. Many of them might prefer to tolerate work conditions, even though stressful, because they feel that alternatives are not available.

Overall, results of the study are consistent with our hypotheses, and with previous findings in the literature. More importantly, they provide additional information on aspects 
that have been insufficiently investigated, such as the role of Sense of Community and of Collective Efficacy. Emergency workers' feeling of belonging to the community where they live and work is a contributor to satisfaction. This finding adds to previous research showing the important role of Sense of Community referred to the "community" of coworkers (Cowman et al. 2004).

These findings provide some suggestions for interventions aimed at enhancing emergency workers' quality of life, particularly among full-time workers, more "vulnerable" than volunteers. More specifically, they indicate the importance of increasing their psychosocial competences (e.g., communication skills, decision making skills, team working, leadership competences, coordination, crowd management skills), besides technical skills. Such competences, according to our results, might constitute important protective factors for rescue workers' quality of life. On this point, a model of non technical skills for members of at risk professions that is currently employed in training courses for emergency workers is NOTECHS model (Flin et al. 1998), including cognitive, behavioral and interpersonal/group skills that all emergency workers (irrespective of their profession) should have, in order to enhance the effectiveness of rescue interventions, and by reflection, their quality of life (Prati et al. 2006).

Some limitations of the study should be acknowledged, however. In particular, the role of the type of profession (e.g., fire fighters, medical service personnel, civic protection personnel) on coping strategies and quality of life could not be addressed in this study and should be considered in future investigations. For example, fire fighters are confronted with partly different events than ambulance personnel and civil protection personnel (e.g., a fire, car accidents, flooding), and these events differ with regard to their impact on a community. Moreover, other sociodemographic and organizational variables are important, besides those ones here considered, for understanding the correlates of quality of life in this population. Finally, as regards the possible influence of the method of data collection (on line questionnaire), we should mention that the questionnaire has been submitted also in face-to-face situations to other groups of emergency workers and preliminary results on over 250 participants confirm the findings obtained in this research.

\section{References}

Alexander, D. A., \& Klein, S. (2001). Ambulance personnel and critical incidents: Impact of accident and emergency work on mental health and emotional well-being. The British Journal of Psychiatry, 178, 76-81. doi:10.1192/bjp.178.1.76.

Bandura, A. (1997). Self-efficacy: The exercise of control. New York: Freeman.

Bandura, A. (2001). Social cognitive theory: An agentic perspective. Annual Review of Psychology, 52, 1-26. doi:10.1146/annurev.psych.52.1.1.

Barbaranelli, C., \& Capanna, C. (2001). Efficacia personale e collettiva nelle associazioni di volontariato socio-assistenziale. In G. V. Caprara (Ed.), La valutazione dell'autoefficacia (pp. 147-156). Trento: Erickson.

Beaton, R., Murphy, S., Johnson, C., Pike, K., \& Cornell, W. (1998). Exposure to duty-related incident stressors in urban fire fighters and paramedics. Journal of Traumatic Stress, 11, 821-828. doi:10.1023/ A: 1024461920456.

Brown, J., Mulhern, G., \& Joseph, S. (2002). Incident-related stressors, locus of control, coping, and psychological distress among firefighters in Northern Ireland. Journal of Traumatic Stress, 15, 161168. doi:10.1023/A:1014816309959.

Carver, C. S. (1997). You want to measure coping but your protocol's too long: Consider the brief COPE. International Journal of Behavioral Medicine, 4, 92-100. doi:10.1207/s15327558ijbm0401_6.

Chang, C. M., Lee, L. C., Connor, K. M., Davidson, J. R., Jeffries, K., \& Lai, T. J. (2003). Posttraumatic distress and coping strategies among rescue workers after an earthquake. The Journal of Nervous and Mental Disease, 191, 391-398. 
Cherniss, C. (1980). Staff burnout: Job stress in the human services. New York: Praeger.

Clohessy, S., \& Ehlers, A. (1999). PTSD symptoms, response to intrusive memories and coping in ambulance service workers. The British Journal of Clinical Psychology, 38, 251-265. doi:10.1348/ 014466599162836.

Cowman, S. E., Ferrari, J. B., \& Liao-Troth, M. (2004). Mediating effects of social support on fire fighters' sense of community and perceptions of care. Journal of Community Psychology, 32, 121-126. doi:10.1002/ jcop. 10089.

Davidson, W. B., \& Cotter, P. R. (1991). The relationship between sense of community and subjective wellbeing: A first look. Journal of Community Psychology, 19, 246-253. doi:10.1002/1520-6629(199107) 19:3<246::AID-JCOP2290190308>3.0.CO;2-L.

Dean, G. P., Gow, K., \& Shakespeare-Finch, J. (2003). Counting the cost: Psychological distress in career an auxiliary fire fighters. Australasian Journal of Disaster and Trauma Studies, 1. Retrieved 20 February 2004 from: http://www.massey.ac.nz/ trauma/issues/2003-1/dean.htm.

DeCarlo, L. T. (1997). On the meaning and use of kurtosis. Psychological Methods, 2, 292-307.

Fabrigar, L. R., Wegener, D. T., MacCallum, R. C., \& Strahan, E. J. (1999). Evaluating the use of exploratory factor analysis in psychological research. Psychological Methods, 4, 272-299. doi:10.1037/ 1082-989X.4.3.272.

Figley, C. R. (1995). Compassion fatigue as secondary traumatic stress disorder. An overview. In C. R. Figley (Ed.), Compassion fatigue (pp. 1-20). New York: Brunner Mazel.

Figley, C. R. (1998). Burnout as systemic traumatic stress: A model for helping traumatized family members. In C. R. Figley (Ed.), Burnout in families: The systemic costs of caring (pp. 15-28). Boca Raton, Florida: CRC Press.

Figley, C. R. (1999). Compassion Fatigue. In B. H. Stamm (Ed.), Secondary traumatic stress: Self-care issues for clinicians, researchers and educators, (2nd ed.) Lutherville, MD: Sidran Press.

Fisher, A. T., \& Sonn, C. C. (Eds.). (2002). Psychological sense of community: Research, applications, and implications. New York: Kluwer Academic/Plenum Publishers.

Flin, R., Goeters, K. M., Hormann, H. J., \& Martin, L.(1998). A generic structure of non-technical skills for training and assessment. Paper presented at the 23rd European Conference of the European Association for Aviation Psychology, Vienna.

Fullerton, R., McCarroll, J., Ursano, R., \& Wright, K. (1992). Psychological responses of rescue workers: Fire fighters and trauma. The American Journal of Orthopsychiatry, 62, 371-377. doi:10.1037/h0079363.

Gibbs, M. S. (1989). Factors in the victim that mediate between disaster and psychopathology: A review. Journal of Traumatic Stress, 2, 489-514.

Hytten, K., \& Hasle, A. (1989). Firefighters: A study of stress and coping. Acta Psychiatrica Scandinavica, 80, 50-55. doi:10.1111/j.1600-0447.1989.tb05253.x.

Jex, S. M., \& Thomas, J. L. (2003). Relations between stressors and group perceptions: Main and mediating effects. Work and Stress, 17, 158-169. doi:10.1080/0267837031000146804.

Marmar, C. R., Weiss, D. S., Metzler, T. J., \& Delucchi, K. (1996). Characteristics of emergency services personnel related to peritraumatic dissociation during critical incident exposure. The American Journal of Psychiatry, 153, 94-102.

Marmar, C. R., Weiss, D. S., Metzler, T. J., Delucchi, K. L., Best, S. R., \& Wentworth, K. A. (1999). Longitudinal course and predictors of continuing distress following critical incident exposure in emergency services personnel. The Journal of Nervous and Mental Disease, 187, 15-22. doi:10.1097/ 00005053-199901000-00004.

Maslach, C., Schaufeli, W. B., \& Leiter, M. P. (2001). Job burnout. Annual Review of Psychology, 52, 397422. doi:10.1146/annurev.psych.52.1.397.

McCammon, S., Durham, T., Jackson Allison, E., \& Williamson, J. (1988). Emergency workers' cognitive appraisal and coping with traumatic events. Journal of Traumatic Stress, 1, 353-372.

McMillan, D. W., \& Chavis, D. M. (1986). Sense of community: A definition and theory. Journal of Community Psychology, 14, 6-23. doi:10.1002/1520-6629(198601)14:1<6::AID-JCOP2290140103>3.0.CO;2-I.

Mitchell, J., \& Bray, G. (1990). Emergency services stress: Guidelines for preserving the health and careers of emergency services personnel. Englewood Cliffs, NJ: Prentice Hall.

Prati, G., Pietrantoni, L., \& Rea, A. (2006). Competenze non tecniche e marcatori comportamentali nelle professioni a rischio. (Non technical competences and behavioral markers in at-risk professions) Nuove Tendenze della Psicologia, 4, 353-370.

Prezza, M., Amici, M., Roberti, T., \& Tedeschi, G. (2001). Sense of community referred to the whole town: Its relations with neighbouring, loneliness, life satisfaction and area of residence. Journal of Community Psychology, 29, 29-52. doi:10.1002/1520-6629(200101)29:1<29::AID-JCOP3>3.0.CO;2-C.

Prezza, M., Costantini, S., Chiarolanza, V., \& Di Marco, S. (1999). La scala italiana del senso di comunità (The Italian scale of sense of community). Psicologia della salute, 3/4, 135-158. 
Raphael, B. (1986). Victims and helpers. In B. Raphael (Ed.), When disaster strikes: How individuals and communities cope with catastrophe (pp. 222-244). New York: Basic Books.

Regehr, C., Hill, J., \& Glancy, G. D. (2000). Individual predictors of traumatic reactions in firefighters. The Journal of Nervous and Mental Disease, 188, 333-339. doi:10.1097/00005053-200006000-00003.

Schafer, J. L. (2000). NORM: Multiple imputation of incomplete multivariate data under a normal model, version 2.03. Software for Windows 95/98/NT. Retrieved 20 February 2004, from: http://www.stat.psu.edu/ jls/misoftwa.html.

Schafer, J. L., \& Graham, J. W. (2002). Missing data: Our view of the state of the art. Psychological Methods, 7, 147-177. doi:10.1037/1082-989X.7.2.147.

Spinhoven, P., \& Verschuur, M. (2006). Predictors of fatigue in rescue workers and residents in the aftermath of an aviation disaster: A longitudinal study. Psychosomatic Medicine, 68, 605-612. doi: 10.1097/01.psy.0000222367.88642.de.

Stamm, B. H. (2002). Measuring compassion satisfaction as well as fatigue: Developmental history of the compassion fatigue and satisfaction test. In C. R. Figley (Ed.), Treating compassion fatigue (pp. 107119). New York: Brunner-Routledge.

Stamm, B. H. (2005). The professional quality of life scale: Compassion satisfaction, burnout, and compassion fatigue/secondary trauma scales. Lutherville, MD: Sidran Press.

Ursano, R. J., Fullerton, C. S., Tzu-Cheg, K., \& Bhartiya, V. R. (1995). Longitudinal assessment of posttraumatic stress disorder and depression after exposure to traumatic death. The Journal of Nervous and Mental Disease, 183, 36-42. doi:10.1097/00005053-199501000-00007.

Wagner, D., Heinrichs, M., \& Eklert, U. (1998). Prevalence of symptoms of posttraumatic stress disorder in German professional firefighters. The American Journal of Psychiatry, 155, 1727-1732.

Weiss, D. S., Marmar, C. R., Metzler, T. J., \& Ronfeldt, H. M. (1995). Predicting symptomatic distress in emergency services personnel. Journal of Consulting and Clinical Psychology, 63, 361-368. doi: 10.1037/0022-006X.63.3.361. 